\title{
No effect of bipolar interferential electrotherapy and pulsed ultrasound for soft tissue shoulder disorders: a randomised controlled trial
}

Institute for

Rehabilitation

Research, Hoensbroek, the Netherlands

G J M G van der Heijden

Netherlands School of Primary Care

Research

G J M G van der Heijden

P Leffers

$\mathrm{H}$ van Mameren

L M Bouter

P G Knipschild

Department of

Epidemiology,

University Maastricht,

the Netherlands

$P$ Leffers

P G Knipschild

Hogeschool Limburg, Faculty of Health, School for

Physiotherapy,

Heerlen, the

Netherlands

P J M C Wolters

J P Houben

Department of

Anatomy and

Embryology,

University Maastricht,

the Netherlands

$\mathrm{H}$ van Mameren

Institute for Research in Extramural

medicine, Vrije

Universiteit,

Amsterdam, the

Netherlands

L M Bouter

Correspondence to:

Dr G J M G van der Heijden,

iRv, Institute for

Rehabilitation Research,

PO Box 192, 6430 AD

Hoensbroek, the

Netherlands.

Accepted for publication

22 March 1999

Geert J M G van der Heijden, Pieter Leffers, Pieter J M C Wolters, José J D Verheijden, Henk van Mameren, Jo P Houben, Lex M Bouter, Paul G Knipschild

\begin{abstract}
Objective-To assess the efficacy of bipolar interferential electrotherapy (ET) and pulsed ultrasound (US) as adjuvants to exercise therapy for soft tissue shoulder disorders (SD).
\end{abstract}

Methods-Randomised placebo controlled trial with a two by two factorial design plus an additional control group in 17 primary care physiotherapy practices in the south of the Netherlands. Patients with shoulder pain and/or restricted shoulder mobility, because of a soft tissue impairment without underlying specific or generalised condition, were enrolled if they had not recovered after six sessions of exercise therapy in two weeks. They were randomised to receive (1) active ET plus active US; (2) active ET plus dummy US; (3) dummy ET plus active US; (4) dummy ET plus dummy US; or (5) no adjuvants. Additionally, they received a maximum of 12 sessions of exercise therapy in six weeks. Measurements at baseline, 6 weeks and $3,6,9$, and 12 months later were blinded for treatment. Outcome measures: recovery, functional status, chief complaint, pain, clinical status, and range of motion.

Results-After written informed consent 180 patients were randomised: both the active treatments were given to 73 patients, both the dummy treatments to 72 patients, and 35 patients received no adjuvants. Prognosis of groups appeared similar at baseline. Blinding was successfully maintained. At six weeks seven patients $(20 \%)$ without adjuvants reported very large improvement (including complete recovery), $17(23 \%)$ and $16(22 \%)$ with active and dummy ET, and $19(26 \%)$ and $14(19 \%)$ with active and dummy US. These proportions increased to about $40 \%$ at three months, but remained virtually stable thereafter. Up to 12 months follow up the $95 \% \mathrm{CI}$ for differences between groups for all outcomes include zero.

Conclusion-Neither ET nor US prove to be effective as adjuvants to exercise therapy for soft tissue SD.

(Ann Rheum Dis 1999;58:530-540)

About $10 \%$ of the population suffer from one or more episodes of shoulder disorders (SD) in the course of their life. ${ }^{1}$ Pain and stiffness in the deltoid region are common symptoms of patients with SD. When pain is elicited or aggravated by movement, it usually limits daily activities and restricts the range of motion. Pain when lying on the impaired shoulder commonly causes problems with sleeping. ${ }^{1-3}$ In a minority of patients SD originate from specific or generalised conditions, such as stroke, polyneuropathy, multiple sclerosis, rheumatoid arthritis, polymyalgia, ankylosing spondylitis, or from malignancies or referred pain from the neck or internal organs. ${ }^{4}$ Localised soft tissue impairment is considered to be the most common source of these symptoms, ${ }^{34}$ while the sympathetic nerve system is suggested to play an important part in causing, amplifying and maintaining pain. ${ }^{5}$

Of all newly presented episodes of SD in Dutch general practice approximately 25\% resolve within one month and about $60 \%$ resolve within six months, but some last over a year. ${ }^{67} \mathrm{~A}$ favourable outcome of SD within three months has been associated with a mild trauma preceding symptoms, ${ }^{68}$ an acute onset of symptoms, ${ }^{9}$ early presentation, ${ }^{6}{ }^{9-11}$ preceding overuse and heavy and unusual activities of the upper extremity. ${ }^{912}$ A poor outcome of SD at approximately three months is reported to be associated with a previous episode, ${ }^{13}$ severe restriction of passive abduction range, ${ }^{13}{ }^{14}$ severe pain at first presentation, ${ }^{6}{ }^{13}$ concomitant neck pain $^{6}$ or cervical spondylosis or radiating pain, ${ }^{15}$ and involvement of the dominant side. ${ }^{916}$

SD make up $10 \%$ of all referrals to physiotherapists. ${ }^{17-20}$ Exercise therapy is considered to be one of the cornerstones of physiotherapy for SD. ${ }^{21}$ In addition, frequent use of transcutaneous electrotherapy and ultrasound, mainly as adjuvants to exercise therapy, has been reported for several countries. ${ }^{22-26}$ Several reviews have shown that relatively few sound studies have been conducted about the effectiveness of ultrasound and and electrotherapy for SD. ${ }^{27-35}$ But, as yet, there seems to be insufficient evidence for the effectiveness of ultrasound and electrotherapy for SD. Both modalities are supposed to add to the effect of exercise therapy in recovery from soft tissue disorders in peripheral joints. Their effect is supposed to depend on the adequacy of the applied dose, rather than on the origin and anatomical site of the soft tissue disorder. The rationale for the use of electrotherapy in the treatment of soft tissue SD is based on the concept of nonpainful transcutaneous stimulus induced analgesia. In this concept, assumptions about increased activity of the sympathetic nerve system in generation and maintenance of pain play a central part. Reduced extensibility of 
subcutaneous soft tissue and increased nocisensoric sensitivity in the lower cervical and upper thoracic dermatomes are considered to be indicators for reactivity of the sympathetic nerve system in SD. ${ }^{36}$ By both central inhibition of activity of the sympathetic nerve system, and peripheral stimulus habituation, electrotherapy is supposed to result electroanalgesic effects, such as increase in the pain threshold and promotion of muscle relaxation. ${ }^{5}{ }^{37}$ The rationale for the use of ultrasound in patients with localised inflammatory conditions of soft tissue, for example, ligaments and tendons, is based on an increase in temperature in soft tissue with a high density of protein. This temperature increase should result in promotion of cellular metabolic rate, acceleration of tissue repair, and reduction of inflammatory reactions. ${ }^{39-41}$ Thereby ultrasound should result in an increase in the pain threshold and reduction of restriction of range of motion.

In this randomised placebo controlled trial we studied the efficacy of bipolar interferential electrotherapy (ET) and pulsed ultrasound (US) as adjuvants to exercise therapy for patients with soft tissue SD. The medical ethics and scientific committee of Maastricht University approved the study design.

\section{Methods}

INCLUSION

Potential participants were patients of 18 years and older, who had been referred to cooperating physiotherapy practices in primary care ( $n=17$; two therapists per practice) by general practitioners or hospital physicians. They had to have pain in the deltoid region that could be elicited or aggravated by movement or a restricted range of glenohumeral motion, or both. They were eligible when the therapist thought US or ET, or both, were indicated. That is he could confirm respectively a localised soft tissue impairment as the probable origin of the symptoms, and/or involvement of the sympathetic nerve system in the perpetuation of the symptoms was very likely. A localised soft tissue impairment was determined by the therapist on the basis of a standardised clinical assessment (details given below, in paragraph on outcome assessment). ${ }^{42}$ The sympathetic nerve system was considered to be involved when the extensibility of subcutaneous soft tissue was reduced and/or the nocisensoric sensitivity in the lower cervical and upper thoracic dermatomes was increased. ${ }^{36}$ Eligible patients willing to participate entered a two week qualification period ${ }^{43}$ with a maximum of six sessions of at least 20 minutes of exercise therapy. Ultimately, the research physiotherapist (JV) decided about inclusion of patients on the basis of a standardised clinical assessment (details given below $)^{42}$ and information obtained from referring physicians about exclusion criteria and contraindications.

EXCLUSION

Before the qualification period the therapists excluded patients who were considered to have major shoulder hypermobility; complete rotator cuff tears; glenohumeral joint inflamma- tion; referred pain from the neck or from internal organs in the shoulder, and patients with suspected or definite diagnosis of a stroke; polyneuropathy; multiple sclerosis; rheumatoid arthritis; polymyalgia; ankylosing spondylitis; malignancy; haemophilia; previous fractures or previous surgery, motor or sensory deficits, wounds or skin defects in the shoulder, upper limb, neck or thorax. The therapists also excluded patients who had already received ET or US during the current episode. After the qualification period the research physiotherapist firstly excluded patients who indicated reluctance to adhere to allocated treatments or to complete follow up. Secondly, she also excluded patients who rated themselves (nearly) completely free of symptoms on a 7 point Likert scale, which was also used for evaluation of the primary outcome measure (see legend of table 2). Thirdly, she excluded patients who indicated very large improvement on the 7 point Likert scale, and at the same time fulfilled three or four of the following putative indicators of a favourable prognosis: (1) only dominant side impaired, (2) first episode ever, (3) no pain radiating below the elbow, (4) no coexistent cervical or elbow disorder. These patients, at the positive end of the prognostic spectrum, were excluded because it is considered unlikely that ET and US can quicken their recovery. Fourthly, she excluded patients who indicated no improvement on the 7 point Likert scale, and at the same time fulfilled three or four of the following putative indicators of a poor prognosis: (1) non-dominant side or bilaterally impaired, (2) previous episodes, (3) pain radiating below the elbow, (4) coexistent cervical or elbow disorder. These patients, at the negative end of the prognostic spectrum, were excluded because it is considered unlikely that they will benefit from the trial treatments.

Patients excluded because they were (nearly) completely free of symptoms, or because they had a very good or a very poor prognosis were followed up at six weeks by postal questionnaire. After providing written consent, the putative prognostic indicators and baseline values of outcome measures of all eligible patients were recorded by the research physiotherapist. Next, treatment was assigned. We asked the patients and therapists to refrain from nonstudy treatments (for example, stroking and kneading massage, deep friction, orthopaedic manipulation and steroid injections) until three months after randomisation. Analgesics and non-steroidal anti-inflammatory drugs (NSAIDS) taken during the qualification period could be continued after randomisation. Their use was monitored.

\section{ELECTROTHERAPY}

A bipolar interferential current was administered. It was a $4 \mathrm{KHz}$ sinusoidal biphasic electric current with an amplitude that was modulated between 60 and $100 \mathrm{~Hz}$, with a ramp and fall of one second each and constant phases of two seconds in between. This electrical current had no resulting galvanic charge. Such a current has been reported to selectively excite 
large diameter nerve fibres. ${ }^{44}$ According to the gate control principle, this excitation is considered to temporarily inhibit transmission of nociceptive signals in the spinal dorsal horn from pain mediating small diameter nerve fibres. ${ }^{37} 3844$ Stimulus habituation should be a precondition for an episode of electroanalgesia. ${ }^{5}$ An intensity sufficient to evoke electric paraesthesia is assumed to result in stimulus habituation. Postponement of stimulus habituation by modulation of amplitude and an increase of the intensity of the current should lengthen the episodes of electroanalgesia. ${ }^{53}$

For each patient two reusable hypoallergic self adhering electrodes $(5 \times 9 \mathrm{~cm})$ were used (Uni-patch Inc, Wabasha, MN 55981, USA); one was placed in the deltoid region, the other over the homolateral erector trunci, parallel to the spine between the processus spinosus of the 4 th and 9th thoracic vertebrae. Stimulation with the deltoid electrode is assumed to produce electroanalgesia in the shoulder by inhibition of signal transmission in the dorsal horn of the 4 th and 5th cervical spinal segments. It has been postulated that sympathetic outflow from the lateral horn of the 4th to the 9th thoracic spinal segments, through the stellate ganglion, sensitises for shoulder pain as a result of which it can cause, amplify, and maintain pain. ${ }^{5}$ Stimulation of large diameter cutaneous nerve fibres of the ramus dorsalis of the 4 th to the 9 th thoracic spinal segments with the thoracic electrode is assumed to diminish this sympathetic outflow to the shoulder and thus contribute to alleviation of shoulder pain. This electrotherapeutical concept is commonly recommended and used. ${ }^{36-38}$ The position of both electrodes was kept fixed during all treatment sessions.

The therapist administered either active or dummy ET according to the instructions from the randomisation envelope. Active ET: the therapist quantified the intensity for the perception threshold of electric paraesthesia at the start of each session. Subsequently, the therapist raised the intensity so that the patient felt intense non-painful electric paraesthesia under both electrodes, without continuous muscle contractions. When after a while stimulus habituation occurred-that is, the electric paraesthesia diminished-the therapist raised the intensity until paraesthesia was felt again. Active ET treatment took maximum 15 minutes, or was stopped earlier after the third habituation. Dummy ET: the therapist quantified the intensity for the perception threshold of electric paraesthesia at the start of each session and repeated this 5, 10, and 15 minutes later. There was no electric output between subsequent determinations of the threshold because after each threshold determination the therapist set the intensity to zero. Hence, specific electric effects could not occur during dummy ET. The duration of dummy ET treatment was fixed at 15 minutes.

\section{ULTRASOUND}

The frequency of the US beam was $0.8 \mathrm{MHz}$, and the effective radiating transducer area was $4 \mathrm{~cm}^{2}$. The beam non-uniformaty ratio ranged from 4 to 6 . During all sessions the US beam was directed at the impaired soft tissue structure. This impairment was determined by the therapist during a standardised clinical assessment at the start of the first session. To reduce the risk of hot spots and subsequent tissue damage because of reflection and interferential phenomena over superficial bone structures, pulsed US with a duty cycle of $20 \%$ (that is, on-off ratio of 2:8) and slow circular transducer movements was applied. The transmission of US was improved by the use of inert aquasonic hypoallergic coupling gel (Chemodis, PO Box 28, 2180 AA Hillegom, NL). Sonation time was fixed at $2 \mathrm{~min} / \mathrm{cm}^{2}$ of the tender area over this structure. An exposure of $50 \mathrm{~J} / \mathrm{cm}^{2}$ is reported to be the threshold for temperature increase in mammalian tissue. ${ }^{41}$ The minimum spatial average temporal average (SATA) transducer output to which the device was to be set was based on the sum of this exposure threshold and the estimated energy absorption between the transducer and the impaired soft tissue structure. During the first session, the therapist calculated the SATA transducer output and the total sonation time. These values were kept constant during all subsequent sessions. The actual application of US was logged by the therapist. Based on the instructions from the randomisation envelope, the therapist set the treatment device to a programmable US code. Only the manufacturer knew the identity of the 10 codes for active and the 10 codes for dummy US.

\section{EXERCISE THERAPY}

At the start of the qualification period, all eligible patients received a booklet containing advice on protection of the shoulder from overuse and continuation of regular activities with the shoulder and upper extremity. The obligatory treatment methods and goals for exercise therapy during and after the qualification period were standardised. Each session of exercise therapy had to be directed at pain reduction and mobility improvement. Exercise methods always had to include active and passive abduction, flexion, internal and external rotation, extension, and adduction. Stretching, functional training and proprioceptive neuromuscular facilitation techniques were optional (additional) exercise methods. Muscle relaxation and strengthening were optional (additional) treatment goals. Each session the therapist logged the actual goal(s) and method(s) used. The intensity of exercise therapy could be adjusted to individual symptoms.

\section{OUTCOME ASSESSMENT}

Patients were asked not to take analgesics or NSAID 24 hours before each outcome assessment. At baseline and during follow up at six weeks, 3, 6, 9 and 12 months patients were asked to rate their overall improvement on a 7 point Likert scale (primary outcome measure: recovery; see legend of table 2). The chief complaint was logged at baseline for each patient, and was defined as an unavoidable painful and/or limited functional activity in which the shoulder is involved. During 
outcome assessments at six weeks and three months, after reviewing their previous scores, patients again were asked to rate their chief complaint. Patient tailored outcome measures, such as recovery and the chief complaint, have been reported to be clinically relevant and sensitive to change. ${ }^{45}$ At baseline and during follow up at six weeks, 3, 6, 9 and 12 months patients were asked to complete the Shoulder Disability Questionnaire (SDQ) for evaluation of the severity of functional status limitation. The SDQ is considered to be sensitive to change in the evaluation of functional status limitation of patients with SD in primary care. ${ }^{46} \mathrm{At}$ baseline and at six week and three month follow up, patients rated the severity of restriction of daily functional activities and various dimensions of shoulder pain during the previous week on a visual analogue scale. These measures are considered to be sensitive to change. ${ }^{46}$ Visual analogue and Likert scales have been reported to be valid and reproducible for measurement of pain and functional capacity, ${ }^{48-51}$ especially for serial measurements when previous scores are made available..$^{52} 53$

At baseline and six weeks and three months thereafter, the research physiotherapist rated symptom severity of all patients on a visual analogue scale. She did this on the basis of a standardised clinical assessment, ${ }^{42}$ including: history; inspection of contour, muscle wasting and swelling; evaluation of pain and active and passive range of motion for abduction, flexion, internal and external rotation, extension and adduction; evaluation of joint play and pain on accessory movements; evaluation of muscle weakness and pain on isometric muscle testing; and palpatory assessment of pain and tissue condition. In addition, after a standardised assessment of active motor tests for which reproducibility has been shown, ${ }^{55}$ she rated restriction of functional mobility of the shoulder on a visual analogue scale. This assessment included judgement of endorotation and exorotation during reaching with the index finger to respectively the heterolateral scapular angulus inferior and the second thoracic processus spinosus; active flexion and abduction; and the glenohumeral-scapulo-thoracic rhythm. The research physiotherapist also checked for side effects of treatments.

DATA ANALYSIS

Missing data of outcome variables were replaced by their foregoing rating. With $20 \%$ of the patients recovered with placebo treatment, a difference of at least $25 \%$ with active or no adjuvant treatment, and an $\alpha$ of $5 \%$ (two sided) and a $\beta$ of $10 \%$, the projected sample size was 70 patients per group. Data analysis was performed with SPSS ${ }^{56}$ and Minitab, ${ }^{57}$ according to the intention to treat principle. ${ }^{58}$ Blinding was broken after completion of the data analysis. Per group we calculated proportions of patients indicating very large improvement (including complete recovery). The calculated $95 \%$ confidence intervals (CI) of differences between groups for these proportions are based on a $\chi^{2}$ test. For all other outcome measures we calculated changes in severity scores for each patient by subtracting the baseline values from the respective follow up values. For all groups these change scores had a non-Gaussian distribution. Therefore, the calculated $95 \%$ CI for median differences between groups were based on the rank sum test. ${ }^{59}$ Interaction between US and ET, and the influence of baseline values of outcome measures, prognostic indicators and the clinical signs and symptoms, on recovery was examined by means of linear multivariable regression analysis. The clinical signs and symptoms concern seven dichotomised variables: presence of a painful arc (yes/no), mobility restriction of the glenohumeral joint (yes/no) or the cervicothoracic spine or adjacent ribs (yes/no); involvement of the rotator cuff muscles (yes/ no), glenohumeral joint capsule (yes/no), m biceps brachii (yes/no) and acromioclavicular joint (yes/no).

ASSIGNMENT

After stratification for physiotherapy practice and involvement of the dominant side, treatment was assigned. To balance treatment groups within the strata, randomised permuted blocks of size 5 per stratum were generated by computer. $^{58}$ With equal weights within the blocks patients were randomised to receive (1) active ET plus active US; (2) active ET plus dummy US; (3) dummy ET plus active US; (4) dummy ET plus dummy US; or (5) no adjuvants. Sealed opaque envelopes were prepared and numbered sequentially. These contained specific instructions for the therapist concerning the use of the treatment device. The research physiotherapist labelled the appropriate envelope with the patient's name and identification number in accordance with the order in which patients enrolled. The envelope was sent to the patient's therapist, who opened it at the first treatment session. In each session the same, fixed sequence of treatments was applied: (1) ET, (2) US, and (3) exercise therapy. Twelve treatment sessions were given over six weeks. Treatment could be stopped before the 12 th session if a patient indicated to be completely free of symptoms, and absence of clinical signs and symptoms was confirmed during clinical assessment.

\section{BLINDING}

The 17 physiotherapy practices were provided with identical equipment (Phyaction 792; Uniphy, PO Box 558, 5600 AN Eindhoven, NL) delivering both US and ET. Every six months, US and ET output was checked and calibrated with a 5\% range when necessary. US and ET without output were used as dummy treatments, while the display of the treatment device was identical for active and dummy treatments. During all treatments the device beeped every 15 seconds and its cooling fan was constantly running. Blinding of therapists and patients for the administration of adjuvant treatment was obviously impossible. In addition, the therapist knew which patient received active or dummy ET. To keep patients blinded, therapists were asked not to talk about the identity of ET with patients. To keep the patient and the therapists 
blinded for the identity of US, the transducer automatically heated to $30^{\circ} \mathrm{C}$ before the US code could be set. To keep the research physiotherapist (JV) blinded during the outcome assessment, patients were instructed not to talk about the assigned treatments with her. To verify blinding of patients for active and dummy treatments six weeks after randomisation, they were asked whether they considered their adjuvant treatment a sham treatment.

\section{Results}

PARTICIPANT FLOW AND FOLLOW UP

Figure 1 summarises the flow of patients through the study. In total 855 patients were screened in participating practices. Some 343 patients entered the qualification period, of whom 180 patients finally were randomised. The mean number of patients recruited per practice was 11 (range: 4-27). In eight practices less than 10 patients were recruited,

\begin{tabular}{|l|l|}
\hline $\begin{array}{l}n=855 \text { Invited to participate } \\
\text { between May } 1992 \text { and } 1 \text { November } 1994\end{array}$ & \\
\hline$n=283$ Unwilling to participate \\
\hline$n=572$ Screened for inclusion by therapists & \\
\hline & $\begin{array}{l}n=99 \text { No pain or restricted range of } \\
\text { movement }\end{array}$ \\
& $n=130$ Fulfilling exclusion criteria \\
\hline
\end{tabular}

$\mathrm{n}=343$ Entered qualification period; 2 weeks with standardised exercise therapy ( $\max 6$ sessions)

$\mathrm{n}=343$ Finally assessed by research therapist before admission

\begin{tabular}{|l|l|}
\hline \multicolumn{1}{|l}{} & $\begin{array}{l}\mathrm{n}=47 \text { Information of referring physician } \\
\text { leading to exclusion }\end{array}$ \\
& $\mathrm{n}=35$ Very favourable prognosis \\
& $\mathrm{n}=49$ Nearly or completely free of symptoms \\
\hline $\mathrm{n}=210$ Qualified for participation & \\
\hline & $\begin{array}{l}\mathrm{n}=2 \text { Very poor prognosis } \\
\text { adhere to treatment }\end{array}$ \\
\hline
\end{tabular}

$\mathrm{n}=180$ Informed consent

6 weeks (maximum 12 sessions)

standardised exercise therapy plus...

Completeness of follow up

- Primary outcome measure

$\mathrm{n}=180$ at 6 weeks and 3 months

$\mathrm{n}=179$ at 6,9 and 12 months

- Other patient measures

$\mathrm{n}=180$ at 6 weeks

$\mathrm{n}=179$ at $3,6,9$ and 12 months

- Research therapist measures

$\mathrm{n}=180$ at 6 weeks

$\mathrm{n}=177$ at 3 months

\begin{tabular}{|c|c|c|c|}
\hline \multicolumn{1}{|c|}{ randomisation } & \multicolumn{3}{c}{} \\
\multirow{4}{*}{ interferential current } & \multicolumn{3}{c}{ pulsed ultrasound } \\
\cline { 2 - 4 } & none & active & dummy \\
\hline none & 35 & & 39 \\
\hline active & & 34 & 39 \\
\cline { 1 - 3 } dummy & & 39 & 33 \\
\hline & 35 & 73 & 72
\end{tabular}

Figure 1 Patient flow diagram. 
Table 1 Prognostic similarity of groups at baseline

\begin{tabular}{|c|c|c|c|c|c|}
\hline & $\begin{array}{l}\text { Active ET } \\
(n=73)\end{array}$ & $\underset{(n=72)}{\text { Dummy } E T}$ & $\begin{array}{l}\text { No ET/no US } \\
(n=35)\end{array}$ & $\begin{array}{l}\text { Active US } \\
(n=73)\end{array}$ & $\underset{(n=72)}{\text { Dummy US }}$ \\
\hline Age (mean $(\mathrm{sd}))$ & $51(14)$ & $50(13)$ & $54(13)$ & $50(13)$ & $51(14)$ \\
\hline Female $(\%)$ & & 56 & 51 & 52 & \\
\hline \multicolumn{6}{|l|}{ Previous episodes (\%) } \\
\hline 0 & 56 & 50 & 60 & 49 & 57 \\
\hline $1-5$ & 33 & 40 & 26 & 36 & 37 \\
\hline$>5$ & 11 & 10 & 14 & 14 & 7 \\
\hline \multicolumn{6}{|l|}{ Coexistent disorders } \\
\hline cervical & 88 & 78 & 77 & 88 & 78 \\
\hline homolateral elbow & 25 & 32 & 31 & 25 & 32 \\
\hline \multicolumn{6}{|l|}{ Impaired shoulder } \\
\hline dominant & 51 & 47 & 54 & 45 & 53 \\
\hline left & 44 & 42 & 34 & 49 & 35 \\
\hline \multicolumn{6}{|l|}{ Duration (\%) (months) } \\
\hline 0 to 3 & 41 & 37 & 37 & 38 & 39 \\
\hline 3 to 6 & 21 & 33 & 26 & 22 & 22 \\
\hline 6 to 12 & 22 & 15 & 20 & 18 & 19 \\
\hline$>12$ & 17 & 15 & 17 & 22 & 10 \\
\hline Pain radiating below elbow (\%) & 75 & 76 & 60 & 67 & 85 \\
\hline Caused by trauma (\%) & 8 & 12 & 17 & 8 & 13 \\
\hline & 68 & 71 & 63 & 66 & 74 \\
\hline \multicolumn{6}{|l|}{ Symptoms before inclusion (\%) } \\
\hline increased & 67 & 73 & 71 & 68 & 72 \\
\hline stable & 8 & 10 & 14 & 7 & 11 \\
\hline decreased & 25 & 17 & 15 & 25 & 17 \\
\hline Prognostic grading ${ }^{\star} \dagger$ & $51(27-68)$ & $48(30-70)$ & $39(25-72)$ & $50(25-70)$ & $50(24-68)$ \\
\hline
\end{tabular}

US=Ultrasoundtherapy; ET=electrotherapy. Because of the factorial trial design the ET groups and the US groups represent the same patients.

$\star$ Prognostic grading by research physiotherapist on a 100 millimetre visual analogue scale (0/100: best/worst), based on a standardised clinical assessment. This assessment involved a standardised history; inspection of contour, muscle wasting and swelling; active and passive evaluation of range of motion and pain on abduction, flexion, internal and external rotation, extension and adduction; evaluation of the functional mobility and active glenohumeral-scapulo-thoracic rhythm; evaluation of joint play and pain on accessory movements; evaluation of muscle weakness and pain on isometric muscle testing; and palpatory assessment of pain and tissue condition. $\mathrm{SD}=$ standard deviation, $\mathrm{n}=$ number of patients, $\dagger$ median (interquartile range).

seven practices recruited between 10 and 20 patients, while one practice recruited 22 and another practice 27 patients. Ten practices together filled up 20 randomised blocks each including five possible treatment combinations (twice four blocks, and each four times one block and two blocks), while seven practices recruited insufficient numbers of patients to fill up at least one block.

The most remarkable difference between the groups at baseline concerns prognostic grading, while minor differences are seen for dominant status of the impaired shoulder, duration of current episode, number or previous episodes and pain radiating below the elbow (table 1). Baseline values of outcome measures seem to be balanced for the compared treatment groups (tables 2 and 3). All randomised patients were present at the six weeks follow up visit. Ratings from the research physiotherapist were missing for three patients who were unable to attend the three month follow up visit. Two of these patients completed and returned questionnaires on patient outcomes by post. By telephone, the third patient reported being completely recovered. After

Table 2 Recovery rates and differences between groups

\begin{tabular}{|c|c|c|c|c|c|}
\hline & $n=73(\%)$ & $n=72(\%)$ & $n=35(\%)$ & $D(95 \% C I)$ & $D(95 \% C I)$ \\
\hline Electrotherapy & Active & Dummy & None & Active dummy & No dummy \\
\hline 6 weeks & \multirow[t]{2}{*}{23} & \multirow[t]{2}{*}{22} & \multirow[t]{2}{*}{20} & $1(-13,15)$ & $-2(-19,15)$ \\
\hline Adjusted & & & & $-1(-15,13)$ & $-0(-18,18)$ \\
\hline 3 months & \multirow[t]{2}{*}{41} & \multirow[t]{2}{*}{39} & \multirow[t]{2}{*}{40} & $2(-14,18)$ & $1(-19,21)$ \\
\hline Adjusted & & & & $-3(-19,13)$ & $-4(-24,17)$ \\
\hline 6 months & \multirow[t]{2}{*}{32} & \multirow[t]{2}{*}{46} & \multirow[t]{2}{*}{34} & $-14(-30,2)$ & $-12(-32,9)$ \\
\hline Adjusted & & & & $-20(-35,-4)$ & $-8(-28,12)$ \\
\hline 9 months & \multirow[t]{2}{*}{40} & \multirow[t]{2}{*}{49} & \multirow[t]{2}{*}{31} & $-9(-25,7)$ & $-18(-37,3)$ \\
\hline Adjusted & & & & $-11(-28,7)$ & $-19(-41,3)$ \\
\hline 12 months & \multirow[t]{3}{*}{37} & \multirow[t]{3}{*}{53} & \multirow[t]{2}{*}{37} & $-16(-32,0)$ & $-16(-36,5)$ \\
\hline Adjusted & & & & $-13(-30,4)$ & $-19(-41,3)$ \\
\hline \multicolumn{4}{|c|}{ Ultrasound therapy } & & \\
\hline 6 weeks & \multirow[t]{2}{*}{26} & \multirow[t]{2}{*}{19} & \multirow[t]{2}{*}{20} & $7(-7,20)$ & $1(-16,17)$ \\
\hline Adjusted & & & & $8(-6,23)$ & $1(-16,19)$ \\
\hline 3 months & \multirow[t]{2}{*}{42} & \multirow[t]{2}{*}{38} & \multirow[t]{2}{*}{40} & $5(-11,21)$ & $3(-18,23)$ \\
\hline Adjusted & & & & $4(-13,20)$ & $-1(-23,21)$ \\
\hline 6 months & \multirow[t]{2}{*}{40} & \multirow[t]{2}{*}{38} & \multirow[t]{2}{*}{34} & $2(-14,18)$ & $-4(-23,17)$ \\
\hline Adjusted & & & & $1(-15,17)$ & $3(-16,21)$ \\
\hline 9 months & \multirow[t]{2}{*}{41} & \multirow[t]{2}{*}{47} & \multirow[t]{2}{*}{31} & $-6(-23,10)$ & $-16(-36,4)$ \\
\hline Adjusted & & & & $-7(-25,10)$ & $-16(-38,6)$ \\
\hline 12 months & \multirow{2}{*}{42} & \multirow[t]{2}{*}{47} & \multirow[t]{2}{*}{37} & $-5(-21,12)$ & $-10(-30,10)$ \\
\hline Adjusted & & & & $-9(-26,8)$ & $-14(-35,7)$ \\
\hline
\end{tabular}

Recovery was rated by patient on an 7 point Likert scale. Presented is the proportion of patients indicating very large improvement (including complete recovery). The complementary proportion reported being much improved, little improved, unchanged, little worse, much worse, very much worse. $\mathrm{D}=$ Differences between groups; negative values denote a difference in favour of the dummy treatment. Adjusted=results of multivariable linear regression analysis with the following co-variables: baseline variables of outcome measures, clinical signs and symptoms (see text), prognostic grading, pain radiating below the elbow, number of prior episodes, duration of current episode, dominant status of impaired side. 
Table 3 Electrotherapy (ET): Medians and interquartile ranges for baseline scores and for changes in scores since baseline and median differences between groups with $95 \%$ confidence intervals

\begin{tabular}{|c|c|c|c|c|c|}
\hline & $\begin{array}{l}\text { Active ET } \\
(n=73)\end{array}$ & $\underset{(n=72)}{\text { Dummy } E T}$ & $\begin{array}{l}\text { No ET } \\
(n=35)\end{array}$ & $\begin{array}{l}\text { Active dummy ET } \\
D(95 \% C I)\end{array}$ & $\begin{array}{l}\text { No dummy ET } \\
D(95 \% C I)\end{array}$ \\
\hline \multicolumn{6}{|c|}{ Chief complaint ${ }^{\star} \dagger$} \\
\hline baseline & $73(53-84)$ & $73(59-86)$ & $70(52-79)$ & & \\
\hline 6 weeks & $24(3-48)$ & $20(0-45)$ & $27(2-42)$ & $-3(-13,6)$ & $4(-7,16)$ \\
\hline 3 months & $36(9-61)$ & $39(18-64)$ & $35(20-57)$ & $4(-6,15)$ & $-3(-15,8)$ \\
\hline \multicolumn{6}{|c|}{ Functional status $† \ddagger$} \\
\hline baseline & $75(63-81)$ & $69(56-87)$ & $75(63-87)$ & & \\
\hline 6 weeks & $8(0-25)$ & $8(-3-31)$ & $9(-6-38)$ & $0(-6, \quad 8)$ & $0(-10,10)$ \\
\hline 3 months & $13(0-38)$ & $21(9-55)$ & $18(7-45)$ & $11(0,19)$ & $-2(-13,8)$ \\
\hline 6 months & $21(-13-56)$ & $31(8-49)$ & $10(-8-60)$ & $7(-6,21)$ & $-10(-26,8)$ \\
\hline 9 months & $34(-2-58)$ & $36(9-57)$ & $24(-3-56)$ & $0(-11,13)$ & $-7(-22,9)$ \\
\hline 12 months & $44(13-63)$ & $44(18-66)$ & $30(-11-44)$ & $3(-9,14)$ & $-19(-37,5)$ \\
\hline \multicolumn{6}{|c|}{ Pain after assessment ${ }^{\star} \dagger$} \\
\hline baseline & $39(11-59)$ & $45(15-64)$ & $33(13-61)$ & & \\
\hline 6 weeks & $12(0-34)$ & $7(0-29)$ & $7(-1-28)$ & $-3(-10,2)$ & $-1 \quad(-9, \quad 6)$ \\
\hline 3 months & $7(-1-36)$ & $14(4-36)$ & $11(0-8)$ & $5(-2,12)$ & $-6(-16,2)$ \\
\hline \multicolumn{6}{|c|}{ Pain yesterday ${ }^{\star} \dagger$} \\
\hline baseline & $46(28-59)$ & $50(30-63)$ & $46(32-61)$ & & \\
\hline 6 weeks & $21(3-39)$ & $9(-1-30)$ & $13(2-21)$ & $-5(-13,2)$ & $2(-6,9)$ \\
\hline \multicolumn{6}{|c|}{ Pain last night ${ }^{\star} \dagger$} \\
\hline baseline & $43(20-67)$ & $50(20-76)$ & $49(24-65)$ & & \\
\hline 6 weeks & $19(2-42)$ & $10(0-30)$ & $15(1-29)$ & $-7(-16,1)$ & $3(-6,13)$ \\
\hline 3 months & $19(0-46)$ & $24(6-46)$ & $18(9-53)$ & $4(-6,14)$ & $0(-10,11)$ \\
\hline \multicolumn{6}{|c|}{ Physical impairment ${ }^{\star} \dagger$} \\
\hline baseline & $43(17-75)$ & $50(24-69)$ & $43(26-65)$ & & \\
\hline 6 weeks & $15(1-29)$ & $13(0-29)$ & $11(0-23)$ & $-1(-8, \quad 4)$ & $-1 \quad(-8,8)$ \\
\hline 3 months & $18(2-39)$ & $23(8-39)$ & $19(4-34)$ & $5(-2,13)$ & $-4(-15,5)$ \\
\hline \multicolumn{6}{|c|}{ Symptom scoret\$ } \\
\hline baseline & $48(28-61)$ & $47(30-63)$ & $50(31-67)$ & & \\
\hline 6 weeks & $20(4-45)$ & $16(4-31)$ & $21(10-29)$ & $-4(-13,4)$ & $3(-5,12)$ \\
\hline 3 months & $21(6-45)$ & $25(10-36)$ & $27(14-32)$ & $1(-8,9)$ & $1(-8,7)$ \\
\hline \multicolumn{6}{|l|}{ Mobility $†$} \\
\hline baseline & $48(16-67)$ & $37(22-68)$ & $44(27-75)$ & & \\
\hline 6 weeks & $10(1-39)$ & $10(-3-27)$ & $14(2-30)$ & $-3(-11,49)$ & $3(-6,13)$ \\
\hline 3 months & $10(0-44)$ & $13(2-31)$ & $15(3-32)$ & $-1(-9, \quad 7)$ & $1(-8,9)$ \\
\hline
\end{tabular}

$\mathrm{D}=$ differences between groups; negative values denote a difference in favour of the dummy treatment. Negative values for median change scores and interquartile ranges denote deterioration. Negative values for differences between groups (D) and $95 \%$ confidence intervals $(\mathrm{CI})$ denote a difference in favour of the dummy group. ${ }^{\star}$ Patient rating for severity during the previous week on a $100 \mathrm{mil}-$ limetre visual analogue scale $(0 / 100$ : best/worst). The chief complaint was logged at baseline, and was defined as an unavoidable painful and/or impaired functioneal activity in which the shoulder is involved. Physical impairment was defined as restriction of functional activities. †Rating of research physiotherapist on a 100 millimetre visual analogue scale (0/100: best/worst), based on a standardised assessment of active mobility: (1) glenohumeral-scapulo-thoracic rhythm; reaching with the index finger to (2) the heterolateral scapular angulus inferior and (3) the second thoracic processus spinosus; (4) flexion and (5) abduction. $\ddagger$ Patient rating for severity of disorder specific functional status limitation during the past 24 hours on the 16 item Shoulder Disability Questionnaire (0/100: best/worst). \$Severity rating of research physiotherapist on a 100 millimetre visual analogue scale $(0 / 100:$ best/worst $)$, based on a standardised clinical assessment. This assessment involved a standardised history; inspection of contour, muscle wasting and swelling; active and passive evaluation of range of motion and pain on abduction, flexion, internal and external rotation, extension and adduction; evaluation of the functional mobility and active glenohumeral-scapulo-thoracic rhythm; evaluation of joint play and pain on accessory movements; evaluation of muscle weakness and pain on isometric muscle testing; and palpatory assessment of pain and tissue condition.

three months, this latter patient was lost to follow up. Sporadically, details of other outcome measures were missing.

PROTOCOL DEVIATIONS

In all, 171 patients (95\%) completed all 12 sessions with the assigned treatment. Patients did not report any side effects. One patient with active US plus dummy ET withdrew from treatment because of complete recovery, and eight patients did so because of symptom deterioration: two without adjuvant treatment, two with both active treatments, one with both placebo treatments, two with dummy ET plus active US, and one with active ET plus dummy US. Up to three months, 173 patients (96\%) did not report to receive any other treatment than was allocated. In all, seven patients received additional corticosteroid injections: one without adjuvant treatment, one with both active treatments, two with dummy ET plus active US, three with active ET plus dummy US.

\section{ELECTROTHERAPY}

For dummy ET the median intensity for the perception threshold of electric paraesthesia was 15 milli-Amperes (interquartile range
(IQR): 9-28). The median intensity of this threshold for active ET, determined at the start of each session, was 14 milli-Amperes (IQR: 10-26). For both groups there was virtually no within subject change during subsequent treatment sessions for this threshold. The three subsequent stimulus habituations during active ET occurred after three minutes (median, range $1-5$ ), with a median intensity of 29,34 , and 39 milli-Amperes, respectively.

\section{ULTRASOUND}

The types of soft tissue disorder chosen as target for treatment were similar for active and dummy US (data not shown). For active US, the median SATA transducer was $0.6 \mathrm{~W} / \mathrm{cm}^{2}$ and the exposure through the identified impaired soft tissue structure was $107 \mathrm{~J} / \mathrm{cm}^{2}$ (median; IQR: 85-124). Although there was no output for dummy US, according to the device setting the transducer output would have been 0.6 $\mathrm{W} / \mathrm{cm}^{2}$, while the exposure would have been $104 \mathrm{~J} / \mathrm{cm}^{2}$ (median; IQR: 87-124). For active US, the skin area that was covered during treatment was $10 \mathrm{~cm}^{2}$ (median; IQR: 8-12), which resulted in a session duration of five minutes (IQR: 4-6). For dummy US $9 \mathrm{~cm}^{2}$ of 
skin was covered (median; IQR: 6-12), which resulted in a session duration of 4.5 minutes (IQR: 3-6).

\section{EXERCISE THERAPY}

Although exercise therapy was not firmly standardised, the groups were similar with respect to the goals of exercise therapy and the methods used. During the qualification period, exercise therapy was aimed at both pain reduction and mobility improvement in five of the six sessions (median; IQR 3-6). During the 12 sessions after randomisation, exercise therapy was aimed at pain reduction in 10 sessions (median; IQR 6-12) and at mobility improvement in 11 sessions (median; IQR 6-12). Muscle relaxation was a treatment goal in half of all sessions.

BLINDING

At six weeks after randomisation 67 patients $(92 \%)$ with active ET and 51 (71\%) with dummy ET believed that they were being treated with active ET. The difference in recovery rates between patients who believed to be treated with active and dummy ET was 5\% (95\% CI: $-14 \%, 23 \%)$. Furthermore, 42 patients $(58 \%)$ with active US and $43(60 \%)$ with dummy US believed that they were being treated with active US. The difference in recovery rates between patients who believed to be treated with active and dummy US was $-1 \%$ (95\% CI: $-15 \%, 13 \%)$.

\section{EFFECT ESTIMATES}

Much or very much deterioration of symptoms was reported by six patients at six weeks: one with both active treatments, one with both dummy treatments, and four with active ET and dummy US; and by four patients at three months: one without and one with both active treatments and two with dummy ET and active US. Up to three months there were virtually no differences between groups for the proportions of patients reporting very large improvement (including complete recovery). At 6, 9, and 12 months the differences between groups for the proportions of patients reporting very large improvement (including complete recovery) were somewhat larger, but never reached the anticipated $25 \%$, while the $95 \%$ CIs generally include zero (table 2). At six weeks and three months there were virtually no differences between groups for median changes in severity scores as baseline of all other outcome measures, and the $95 \%$ CIs always include zero

Table 4 Ultrasound therapy (US): medians and interquartile ranges for baseline scores and for changes in scores since baseline and median differences between groups with $95 \%$ confidence intervals

\begin{tabular}{|c|c|c|c|c|c|}
\hline & $\begin{array}{l}\text { Active US } \\
(n=73)\end{array}$ & $\begin{array}{l}\text { Dummy US } \\
(n=72)\end{array}$ & $\begin{array}{l}\text { No US } \\
(n=35)\end{array}$ & $\begin{array}{l}\text { Active dummy US } \\
D(95 \% C I)\end{array}$ & $\begin{array}{l}\text { No dummy US } \\
D(95 \% C I)\end{array}$ \\
\hline \multicolumn{6}{|c|}{ Chief complaint ${ }^{\star} \dagger$} \\
\hline baseline & $73(55-84)$ & $75(59-90)$ & $70(52-79)$ & & \\
\hline 6 weeks & $22(2-55)$ & $22(1-44)$ & $27(2-42)$ & $-3(-12,6)$ & $-4(-15,7)$ \\
\hline 3 months & $31(14-61)$ & $41(16-62)$ & $35(20-57)$ & $3(-6,15)$ & $3(-2,16)$ \\
\hline \multicolumn{6}{|c|}{ Functional status $† \ddagger$} \\
\hline baseline & $69(56-81)$ & $75(63-87)$ & $75(63-87)$ & & \\
\hline 6 weeks & $11(0-31)$ & $7(-3-20)$ & $9(-6-38)$ & $-6(-13,2)$ & $-2(-13,7)$ \\
\hline 3 months & $23(0-47)$ & $15(0-51)$ & $18(7-45)$ & $-3(-13,7)$ & $-4(-16,7)$ \\
\hline 6 months & $36(6-52)$ & $25(-3-50)$ & $10(-8-60)$ & $-3(-16,9)$ & $3(-13,21)$ \\
\hline 9 months & $33(1-56)$ & $38(9-60)$ & $24(-3-56)$ & $2(-10,14)$ & $7(-9,23)$ \\
\hline 12 months & $38(8-63)$ & $49(25-65)$ & $30(-11-44)$ & $9(-2,20)$ & $23(7,39)$ \\
\hline \multicolumn{6}{|c|}{ Pain after assessment ${ }^{\star} \dagger$} \\
\hline baseline & $34(8-52)$ & $48(22-65)$ & $33(13-61)$ & & \\
\hline 6 weeks & $9(0-32)$ & $7(0-31)$ & $7(-1-28)$ & $-1(-6, \quad 5)$ & $3(-4,12)$ \\
\hline 3 months & $11(0-35)$ & $14(2-39)$ & $11(0-28)$ & $2(-5, \quad 9)$ & $4(-4,15)$ \\
\hline \multicolumn{6}{|c|}{ Pain yesterday ${ }^{\star} \dagger$} \\
\hline baseline & $46(25-55)$ & $51(31-67)$ & $46(32-61)$ & & \\
\hline 6 weeks & $12(0-32)$ & $13(1-34)$ & $13(2-21)$ & $1(-7,8)$ & $1(-7,10)$ \\
\hline baseline & $44(20-71)$ & $48(20-72)$ & $49(24-65)$ & & \\
\hline 6 weeks & $12(0-49)$ & $15(0-30)$ & $15(1-29)$ & $-4(-14,4)$ & $-1(-10,8)$ \\
\hline 3 months & $25(1-51)$ & $19(1-45)$ & $18(9-53)$ & $-2(-12,8)$ & $-3(-14,7)$ \\
\hline \multicolumn{6}{|c|}{ Physical impairment ${ }^{\star} \dagger$} \\
\hline baseline & $49(19-67)$ & $49(20-77)$ & $43(26-65)$ & & \\
\hline 6 weeks & $15(0-29)$ & $13(1-30)$ & $11(0-23)$ & $0(-6, \quad 6)$ & $1(-7,9)$ \\
\hline 3 months & $20(2-39)$ & $22(4-39)$ & $19(4-34)$ & $1(-7,9)$ & $2(-7,13)$ \\
\hline \multicolumn{6}{|c|}{ Symptom scorets } \\
\hline baseline & $49(27-60)$ & $47(32-65)$ & $50(31-67)$ & & \\
\hline 6 weeks & $18(4-34)$ & $13(4-37)$ & $21(10-29)$ & $-2(-10,7)$ & $-2(-12,8)$ \\
\hline 3 months & $23(8-40)$ & $23(8-42)$ & $27(14-32)$ & $0(-7,9)$ & $0(-8,10)$ \\
\hline \multicolumn{6}{|l|}{ Mobility $\dagger$} \\
\hline baseline & $44(17-68)$ & $39(19-64)$ & $44(27-75)$ & & \\
\hline 6 weeks & $9(1-30)$ & $10(-4-32)$ & $14(2-30)$ & $-1\left(\begin{array}{ll}-7, & 8\end{array}\right)$ & $-1 \quad(-12,10)$ \\
\hline 3 months & $13(1-37)$ & $12(1-38)$ & $15(3-32)$ & $1(-8,7)$ & $0(-10,10)$ \\
\hline
\end{tabular}

$\mathrm{D}=$ differences between groups; negative values denote a difference in favour of the dummy treatment. Negative values for median change scores and interquartile ranges denote deterioration. Negative values for differences between groups (D) and $95 \%$ confidence intervals (CI) denote a difference in favour of the dummy group. ${ }^{\star}$ Patient rating for severity during the previous week on a 100 millimetre visual analogue scale $(0 / 100$ : best/worst). The chief complaint was logged at baseline, and was defined as an unavoidable painful and/or impaired functioneal activity in which the shoulder is involved. Physical impairment was defined as restriction of functional activities. †Rating of research physiotherapist on a 100 millimetre visual analogue scale (0/100: best/worst), based on a standardised assessment of active mobility: (1) glenohumeral-scapulo-thoracic rhythm; reaching with the index finger to (2) the heterolateral scapular angulus inferior and (3) the second thoracic processus spinosus; (4) flexion and (5) abduction. $\ddagger$ Patient rating for severity of disorder specific functional status limitation during the past 24 hours on the 16 item Shoulder Disability Questionnaire (0/100: best/worst). \$Severity rating of research physiotherapist on a 100 millimetre visual analogue scale $(0 / 100:$ best/worst $)$, based on a standardised clinical assessment. This assessment involved a standardised history; inspection of contour, muscle wasting and swelling; active and passive evaluation of range of motion and pain on abduction, flexion, internal and external rotation, extension and adduction; evaluation of the functional mobility and active glenohumeral-scapulo-thoracic rhythm; evaluation of joint play and pain on accessory movements; evaluation of muscle weakness and pain on isometric muscle testing; and palpatory assessment of pain and tissue condition. 
(tables 3 and 4). When restricted to the filled blocks only, the analyses yielded similar results (data not shown). The linear regression analysis showed that at six weeks the effect of the combination of ET and US on the recovery rate was $10 \%$ higher ( $95 \% \mathrm{CI}:-18 \%, 37 \%$ ) than for ET or US alone. The interaction effect became smaller with wider CIs during later follow up. In a multivariable linear regression analysis, the baseline values of outcome measures, clinical signs and symptoms and unbalanced putative prognostic indicators (dominant status of the impaired shoulder, duration of current episode, number or previous episodes, pain radiating below the elbow and prognostic grading) did not show any influence on differences in recovery between active and dummy treatment or between dummy treatment and no adjuvants (table 2). Neither did these covariables change the results for any other outcome measure (data not shown).

At six week follow up the two patients excluded for their poor prognostic status at baseline reported their referral to a hospital specialist for consultation. At six week follow up $58 \%$ of 84 patients excluded because of their favourable prognosis at baseline reported very large improvement (including complete recovery); a recovery rate that was never reached by the trial participants. Of the 49 subjects who were excluded at baseline because they were nearly or completely free of symptoms, $10(20 \%)$ did not return the six week follow up questionnaire, while $35(71 \%)$ of them reported very large improvement (including complete recovery). In addition, $14(40 \%)$ of the 35 subjects excluded because of their very favourable prognostic status reported very large improvement (including complete recovery). The trial participants reached this recovery rate only six weeks later.

\section{Discussion}

The primary goal of our study was to assess whether ET and US add to the effect of exercise therapy for SD. A secondary goal was to examine the magnitude of a potential placebo effect of ET and US. We used a factorial study design because of its statistical efficiency. Antagonism between ET and US is considered unlikely, because their use is based on different biological mechanisms and processes of disease. Moreover, the magnitude of interaction shown by our data was neither clinical relevant nor statistically significant. Most patients improved over time, irrespective of the treatment allocated. The proportion of patients with very much improvement or complete recovery for the whole population was $22 \%$ at six weeks and increased to $40 \%$ at three months. The absence of differences in improvement between groups is consistent for all outcome measures. Adjustment for various potentially relevant covariables did not change the results. All reported differences between groups are considered to be too small to be clinical relevant. At six weeks, the statistical power (1- $\beta$, two sided $\alpha=5 \%$ ) to detect a difference in recovery rates of at least $25 \%$ between active and dummy ET is $90 \%$ and
$92 \%$ for such differences between active and dummy US. After three months, statistical power for both treatment comparisons still was $88 \%$. In addition, none of the CIs included the anticipated difference of $25 \%$ in favour of active treatments. Therefore, we consider it unlikely that we have missed a large effect of ET and US.

STUDY POPULATION AND SIMILARITY OF GROUPS The outcome at six weeks of the subgroup of patients who were excluded because of their favourable prognosis at baseline, indeed, turned out to be more beneficial than for the randomised patients. Participation of this subgroup would have reduced the efficiency of our study considerably. We confined participation to a patients with SD, which according to current understanding of the mechanisms of action were considered most susceptible to US and ET. In addition, we restricted enrolment to patients who were highly motivated to adhere to treatment and to complete follow up. As no benefit could be demonstrated, less motivated patients with less susceptible SD are less likely to benefit from ET and US.

We did not limit enrolment to one specific type of soft tissue SD or diagnostic subgroup. It has been argued that the prognosis may vary according to the type of SD, and likewise that different diagnosis or types of SD warrant particular interventions. But, as yet, there is no convincing evidence for both the accuracy and the (prognostic) validity of the popular diagnostic classification systems. ${ }^{60-65}$ Futhermore, there is no convincing evidence to support assumptions about differential effects of ET and US in any subgroup of SD. Therefore, we neither excluded patients nor stratified participants according to a diagnostic classification system.

After randomisation baseline values of outcome measures seemed to be balanced between groups. In a multivariable regression analysis, the few differences regarding prognostic status at baseline did not change the results. Furthermore, it does not seem likely that the few protocol violations (that is, treatment withdrawal, loss to follow up, and non-study treatment) have resulted in bias of any importance. Their negligible number can be explained by the restriction of enrolment to patients willing to adhere to the allocated treatment and to complete follow up.

BLINDING

ET and US without output were used to control for potential placebo effects. Therapists could be blinded for the identity of US, but not for the identity of ET. The patients and the research physiotherapist were kept blinded for the identity of active and dummy treatments. Blinding of patients for treatment identity was considered to be successful, as active and dummy treatments seemed equally convincing to patients. Identification of the true nature of treatments at six weeks did not seem to be related to their effect. Therefore, it is not likely that unmasking of their nature resulted in bias of any importance. 
TREATMENT CONTRASTS

Central inhibition of activity of the sympathetic nerve system and peripheral stimulus habituation, are supposed to occur during active ET and not during dummy ET. Hence, active ET was expected to support recovery. Although we observed an increase in the sensoric threshold during subsequent active ET sessions, we could not demonstrate a beneficial effect in favour of active ET. While intermittent US and slow circular transducer movements both reduce the risk of tissue damage, a $0.8 \mathrm{MHz}$ US beam possesses sufficient penetration for the shoulder region. The administered exposure was much higher than the $50 \mathrm{~J} / \mathrm{cm}^{2}$ threshold for temperature increase and was therefore expected to promote recovery. Nevertheless, we have not been able to demonstrate beneficial effects in favour of active US. It is not likely that the benefit of an increased dose of ultrasound exposure, if any, would outweigh the potential risk of tissue damage.

The groups were similar with respect to the methods used and goals of exercise therapy. We standardised goals and techniques for exercise therapy, to control for bias attributable to differences between the groups for the content of exercise therapy. This was necessary because it was impossible to blind the therapists for the contrasts between exercise therapy with and without modality and between active and placebo electrotherapy. Further standardisation was considered unnecessary. To reduce the effect of any residual variation in exercise therapy between therapists, treatment was assigned in blocks, after stratification per practice. When the analyses were restricted to the filled blocks, they yielded similar results. Therefore it is unlikely that an effect of exercise therapy confounded the results. Hence, it must be concluded that ET and US, adjuvant to exercise therapy, are not effective in the treatment of patients with soft tissue SD.

To study the magnitude of a potential placebo effect we included a control group without adjuvant treatment. This treatment comparison could not be blinded for therapists and patients, but the groups were similar as far as exercise therapy was concerned. Only the outcome assessment by the research physiotherapist was blinded. But, we could demonstrate neither a clinically relevant nor a statistically significant difference in favour of dummy ET and dummy US for any of the outcome measures. Therefore, a placebo effect of ET and US is also considered to be unlikely.

In conclusion, during the design and conduct of our study, we believe that we have been able to overcome the most important potential threats to validity. The statistical power of the study always exceeds $85 \%$ - that is, the chance that we have missed a difference between the groups for recovery of at least $25 \%$ is always lower than $15 \%$. Consequently, the results permit a clear conclusion: neither ET nor US prove to be effective as adjuvants to exercise therapy for soft tissue SD. Thus far, there is no convincing evidence from randomised clinical trials for the effectiveness of ET and US. ${ }^{27-35}$
Although relatively promising results have been reported for the effectiveness of exercise therapy in patients with $\mathrm{SD}^{66}{ }^{67}$ there is convincing evidence that corticosteroid injections are more effective as primary care treatment for SD than physiotherapy, ${ }^{68-71}$ while it is likely that NSAIDs and analgesics are more (cost)effective than physiotherapy. ${ }^{72}$ Hence, for future studies priority should be given to a comparison of the (cost) effectiveness of exercise therapy, NSAIDs, and analgesics. For such a study, inclusion of a no treatment control group (for example, rest, waiting list) should be considered.

1 Croft P. Soft-tissue rheumatism. In: Silman AJ, Hochberg MC, eds. Epidemiology of the rheumatic diseases. Oxford Oxford University Press, 1993:375-421.

2 Jayson MIV. Frozen shoulder: adhesive capsulitis. BMJ 1981;283:1005-6.

3 Bland JH, Merit JA, Boushey DR. The painful shoulder. Semin Arthritis Rheum 1977;7:21-47.

4 Uthoff HK, Sarkar K. An algorithm for shoulder pain caused by soft-tissue disorders. Clin Orthop 1990;254: $121-7$.

5 Roberts WJ. A hypothesis on the physiological basis for causalgia and related pains. Pain 1986;24:179-311.

6 Van der Windt DAWM, Koes BW, Boeke AJP, Devillé W, De Jong BA, Bouter LM. Shoulder disorders in general Jong BA, Bouter LM. Shoulder disorders in general
practice: prognostic indicators of outcome. Br J Gen Pract

7 Van der Windt DAWM, Koes BW, Boeke AJP, Devillé W, De Jong BA, Bouter LM. Shoulder disorders in general practice: incidence, patient characteristics and management. Ann Rheum Dis 1995;54:959-64.

8 Yamanaka K, Matsumoto T. The joint side tear of the rotator cuff. A follow-up study by athrography. Clin Orthop 1994;304:68-73

9 Chard MD, Satelle LM, Hazleman BL. The long term outcome of rotator cuff tendinitis. A review study. Br J Rheumatol 1988;27:385-9.

10 Bulgen DY, Binder AI, Hazleman BL, Dutton J, Roberts S. Frozen shoulder; prospective clinical study with an evaluaFrozen shoulder; prospective clinical study with an evalua-
tion of three treatment regimens. Ann Rheum Dis 1984;43:353-60.

11 Hazleman BL. The painfull stiff shoulder. Rheumatol Phys Med 1972;11:413-20.

12 Sobel JS, Winters JC, Arendzen JH, Groenier KH, Meyboom-De Jong B. Schouderklachten in de huisartspraktijk. Huisarts Wet 1995;38:342-7.

13 Croft P, Pope D, Silman A. The clinical course of shoulder pain: prospective cohort study in primary care. BMJ 1996; 313:601-2

14 Mulcahy KA, Baxter AD, Oni OOA, Finlay D. The value of shoulder distension artrography with intraarticular injection of steoris ans local anaesthetic: a follow-up study. Br J Radiol 1994;67:263-6.

15 Pollock RG, Duralde XA, Flatow EL, Bigliani LU. The use of arthroscopy in the treatment of resistant frozen shoulder. of arthroscopy in the treatme

16 Binder AI, Bulgen DY, Hazleman BL, Roberts S. Frozen shoulder; a long-term prospective study. Ann Rheum Dis 1984;43:361-4

17 Grundemeijer HGLM, Brouwer HJ. De betekenis van fysiotherapie bij aandoeningen aan het bewegingsapparaat Huisarts en wetenschap 1983;31 (suppl 12):44-59.

18 Peters D, Davies P, Pietroni P. Musculoskeletal clinic in general practice: study of one year's referrals. Br J Gen Pract 1994;44:25-9.

19 Hackett GI, Bundred P, Hutton JL, O’Brien J, Stanley IM Management of joint and soft-tissue injuries in three general practices: value of on-site physiotherapy. $\mathrm{Br} \mathrm{J} \mathrm{Gen}$ Pract 1993;43:61-4

20 Gentle PH, Herlihy PJ, Roxburgh IO. Controlled trial of an open-access physiotherapy service. Br J Gen Pract 1994:34:371-6

21 Rush PJ, Shore A. Physician perceptions of the value of physical modalities in the treatment of musculoskeletal disease. Br J Rheumatol 1994;33:566-8.

22 Lindsay DM, Dearness J, McGinley CC. Electrotherapy usage trends in private practice in Alberta. Physiotherapy Canada 1995;47:30-4.

23 Pope GD, Mocket SP, Wright JP. A survey of electrotherapeutic modalities: ownership and use in the NHS in England. Physiotherapy 1995;81:82-91.

24 Robinson A, Snyder-Mackler L. Clinical application of electrotherapeutic modalities. Phys Ther 1988;68:1235-38.

25 Haar G ter, Dyson M, Oakley EM. The use of ultrasoundtherapy by physiotherapists in Britain, 1985. Ultrasoundtherapy in Medicine and Biology 1987;13:659-63.

26 Annual Report. Executive board of the Health Insurance Council. Amstelveen, the Netherlands: Klomp and Bosman, 1990.

27 Van der Heijden GJMG, Van der Windt DAWM, DeWinter AF. Physiotherapy for soft-tissue shoulder disorders. A systematic review of randomized clinical trials. BMJ 1997; 315:25-30. 
28 Rey B, Gerber NJ. Shoulder pain trials. In: Slapbach P, Gerber NJ, eds. Physiotherapy: controlled trials and facts. Rheumatology (vol 14). Basel: Karger, 1991:91-8.

29 Van der Heijden GJMG, Torenbeek M, Van der Windt DAWM, Hidding A, Dekker J, Bouter LM. Transcutaneou electrotherapy for musculoskeletal disorders: A systematic review. Final report for the Health Council of the Netherlands. Hoensbroek: Institute for Rehabilitation Research, 1999.

30 Van der windt DAWM, Van der Heijden, Van den Berg SGM, Ter Riet G, De Winter AF, Bouter LM. Ultrasound for musculoskeletal disorders: A systematic review. Pain (in press).

31 Green S, Buchbinder R, Glazier R, Forbes A. Systematic review of randomised controlled trials of interventions for painful shoulder: selection criteria, outcome assessment, and efficacy. BMJ 1998;316:354-60.

32 Gam AN, Johannsen F. Ultrasound therapy in musculoskeletal disorders: a meta-analysis. Pain 1995;63:85-91.

33 Kitchen SS, Partridge J. A review of therapeutic ultrasound. Physiotherapy 1990;76:593-600.

34 Falconer J, Hayes KW, Chang RW. Therapeutic ultrasound in the treatment of musculoskeletal conditions. Arthriti Care Research 1990;3:85-91.

35 Robinson AJ. Transcutaneous electrical nerve stimulation for the control of pain in musculoskeletal disorders. J Orthop Sports Phys Ther 1996;24:208-26.

36 Van Zutphen (91-2) HCF, Oostendorp RAB, Rens PPThG van, Bernards ATM, eds. Nederlands lecrboek der fysische therapie in engere zin. VB. Elektrotherapie ter bestrijdisische therapie in engere zin. $V B$. Elektrotherapie ter bestrijding van pijn en vegetatieve stoornissen. Utre

37 Sjölund BH, Eriksson M, Loeser JD. Transcutaneous and implanted electric stimulation of pheripheral nerves. In Bonica JJ, ed. The management of pain. Philadelphia: Lea and Febiger, 1990.

38 Devor M. Peripheral and central nervous system mechanisms of sympathetic related pain. Pain Clinic 1995;8:5 14.

39 Hayes KW. The use of ultrasoundtherapy to decrease pain and improve mobility. Critical Reviews in Physical and Rehabilitation Medicine 1992;3:271-87.

40 Sweitzer RW. Ultrasound. In: Hecox B, Weisberg J, Tsega AM, eds. Physical agents. Connecticut: Appleton and Lange, 1994:163-92.

41 Dunn F, Frizzel LA. Bioeffects of ultrasoundtherapy. In Lehman JF, ed. Therapeutic heat and cold. Baltimore: Lehman JF, ed. Therapentic

42 Corrigan B, Maitland GD. Muskuloskeletal and sports injuries. Oxford: Butterworth-Heineman, 1994;38-65.

43 Knipschild P, Leffers P, Feinstein AR. The qualification period. J Clin Epidemiol 1991;44:461-4

44 Sato A, Schmidt RF. Somatosympathetic reflexes: afferen fibers, central pathways, discharge characteristics. Physio Rev 1973;53:916-45

45 Guyatt GH, Walter S, Norman G. Measuring change over time. Assessing the usefulness of evaluative instruments. Journal of Chronic Diseases 1987;40:171-8.

46 Van der Heijden GJMG, Leffers P, Bouter LM. Development and responsiveness of the Shoulder Disability Questionnaire. J Clin Epidemiol (in press).

47 Van der Windt DAWM, Van der Heijden GJMG, Koes BW, Bouter LM. The responsiveness of the shoulder disability questionnaire. Ann Rheum Dis 1998;57:82-7.

48 Jaeschke R, Singer J, Guyatt GH. A comparison of seven-point and visual analogue scales. Control Clin Trials seven-point and

49 Carlsson AM. Assessment of chronic pain. I. Aspects of reliability and validity of the visual analogue scale. Pain 1983; 16:87-101

50 Revill SI, Robinson JO, Rosen M, Hogg MIJ. The reliability of a linear analogue for evaluating pain. Anaesthesia 1976; $31: 1191-8$

51 Scott JP, Huskinsson EC. Measurement of functional capacity with visual analogue scales Rheumatology and Rehabilitation 1977;16:257-9.
52 Guyatt GH, Berman LB, Townsend M, Taylor DW. Should study subjects see their previous responses? Journal of Chronic Diseases 1985;38:1003-7.

53 Scott J, Huskinsson EC. Accuracy of subjective measurements made with or without previous scores: an important source of error in serial measurements of subjective status. Ann Rheum Dis 1979;38:588-9.

54 Westerberg CE, Solem-Bertoft E, Lundh I. The reliabillity of three active motor tests used in painful shoulder disorders. Scand J Rehab Med 1996;28:63-70.

55 Solem-Bertoft E, Lundh I, Westerberg CE. Pain is a major determinant of impaired performance in standardized active motor tests. Scand J Rehab Med 1996;28:71-8.

56 Norusis MJ. SPSS for Windows, Release 5.0. Chicago: SPSS Inc, 1992.

57 Minitab Inc. Minitab, Release 9. Lebanon: Sowers Printing Company, 1992.

58 Meinert CL. Clinical trials. New York: Oxford University Press, 1986.

59 Brown BW, Hollander M. Statistics. A biomedical introduction. New York: John Wiley, 1977:327-39.

60 Ure BM, Tilling T, Kirchner R, Rixen D. Zuverlässigkeit der klinischen Untersugung der Schulter im vergleigh zur Arthroskopie. Unfallchirurg 1993;96:382-6.

61 Bamji AN, Erhardt CC, Price TR, Williams PL. The painful shoulder: can consultants agree? Br J Rheumatol 1996; $35: 1172-4$

62 Liesdek C, Windt DAWM van der, Koes BW, Bouter LM. Soft-tissue disorders of the shoulder. A study of interobserver agreement between general practitioners an physiotherapists and an overview of physiotherapeutic physiotherapists and an overview of physi
treatment. Physiotherapy 1997;83:12-17.

63 De Winter AF, Jans MP, Scholten RJPM, Deville W, Schaardenburg D, Bouter LM. Diagnostic classification of shoulder disorders: inter-observer agreement and determinants of disagreement. Ann Rheum Dis (in press).

64 Pellecchia GL, Paolino J, Connell J. Inter-tester reliability of the Cyriax evaluation in assessing patients with shoulder pain. J Orthop Sports Phys Ther 1996;23:34-8.

65 Buchbinder R, Goel V, Bombardier C, Hogg-Johnson S. Classification systems of soft tissue disorders of the neck and upper limb: do they satisfy methodological guidelines? J Clin Epidemiol 1996;49:141-9.

66 Brox JI, Staff PH, Ljunggren AE, Brevik JI. Arthroscopic surgery compared with supervised exercises in patients with rotator cuff disease (stage II impingement syndrome) BMJ 1993;307:899-903.

67 Ginn KA, Herbert RD, Khouw W, Lee R. A randomized, controlled clinical trial of treatment for shoulder pain. Phys Ther 1977;77:802-11.

68 Van der Heijden GJMG, Van der Windt DAWM, Kleijnen J, Koes BW, Bouter LM. Steroid injections for shoulder disorders: a systematic review of randomized clinical trials. Br J Gen Pract 1996; 46:309-16.

69 Goupille P, Sibillia J. Local corticosteroid injections in the treatment of rotator cuff tendinitis. Clin Exp Rheumatol 1996;14:561-6.

70 Van der Windt DAWM, Koes BW, Devillé W, Boeke AJP, De Jong BA, Bouter LM. Effectiveness of corticosteroid injections versus physiotherapy for treatment of painful stiff shoulder in primary care: randomised trial. BMJ 1998;317: 1292-6.

71 Winters JC, Sobel JS, Groenier, Arendzen HJ, Meyboom-De Jong B. Comparison of physiotherapy, manipulation and corticosteroid injection for treating manipulation and corticosteroid injection for treating shoulder

72 Van der Windt DAWM, Van der Heijden GJMG, Scholten RJPM, Koes BW, Bouter LM. The efficacy of non-steroidal anti-inflammatory drugs (NSAIDS) for shoulder complaints. A systematic review. J Clin Epidemiol 1995;48:691-704. 